\title{
Perubahan Posisi Mandibula pada Perawatan Kamuflase Maloklusi Kelas III Skeletal
}

\author{
Sri Hartati*, Heryumani JCP**, dan Kuswahyuning ** \\ * Program Studi Ortodonsia PPDGS Fakultas Kedokteran Gigi Universitas Gadjah Mada \\ ** Bagian Ortodonsia, Fakultas Kedokteran Gigi Universitas Gadjah Mada \\ *JI Denta no 1 Sekip Utara Yogyakarta; e-mail: srihartatidrg67@yahoo.com
}

\begin{abstract}
ABSTRAK
Maloklusi kelas III skeletal pada umumnya memiliki hubungan rahang yang prognatik, yaitu mandibula terletak lebih maju dari maksila. Perawatan kamuflase non pembedahan pada pasien dewasa dengan maloklusi kelas III memerlukan pencabutan dua gigi premolar mandibula atau empat gigi premolar untuk memberikan ruang retraksi gigi incisivus mandibula. Prinsip perawatan teknik Begg adalah mekanisme gaya differensial dengan menggunakan gaya yang ringan dan kontinyu. Penggunaan elastik intermaksiler kelas III menyebabkan ekstrusi gigi molar atas, retrusi gigi insisivus bawah, rotasi mandibula searah jarum jam dan perubahan posisi kondilus. Penelitian ini bertujuan untuk mengetahui perubahan linier dan anguler posisi mandibula pada perawatan kamuflase maloklusi kelas III skeletal setelah dilakukan perawatan ortodontik dengan teknik Begg. Penelitian dilakukan pada 20 pasang sefalogram lateral dari subjek laki-laki dan perempuan usia 18-25 tahun yang memenuhi kriteria penelitian. Seluruh subjek yang dirawat dengan teknik Begg disertai pencabutan dua gigi premolar pertama bawah. Perubahan posisi mandibula ditentukan dengan perubahan titik Pg dan Pg. terhadap sumbu X dan sumbu $Y$ sedangkan perubahan anguler dengan melihat perubahan sudut $Y$-axis. Data yang diperoleh dianalisisi dengan paired $t$ test. Hasil penelitian perubahan posisi mandibula setelah perawatan ortodontik kamuflase dengan alat cekat teknik Begg menunjukkan perubahan yang bermakna $(\mathrm{p}<0,05)$. Titik Pg mengalami pergeseran ke arah posterior dan inferior dan sudut $\mathrm{Y}$-axis mengalami peningkatan berarti terjadi rotasi searah jarum jam.
\end{abstract}

Maj Ked Gi; Desember 2013; 20(2): 140 - 145.

Kata kunci: posisi mandibula, kamuflase, skeletal, klass III, teknik Begg

ABSTRACT: Skeletal Class III malocclusion generally has prognatic jaw relationship. The mandibular is more forward than the maxilla. Camouflage non-surgical treatment in adult patients with Class III malocclusion required extraction of two mandibular premolars or four premolar teeth to give a space of mandibular incisors teeth retraction. The Begg technique treatment principle is the mechanism of differential force using light and continuous force. The use of inter-maxillary elastic Class III causes the extrusion of upper molars, retrusion of lower incisors, clockwise rotation of the mandible and changing of condyle position. This research aims to determine the linear changing and angular position of the mandible on the camouflage treatment of skeletal Class III malocclusion after orthodontic treatment with Begg technique. The research was conducted on 20 pairs of lateral cephalogram of men and women aged 18-25 years who met the research criteria. All subjects were treated with Begg technique with extraction of two lower first premolars. The changing of mandibular position is determined by changing the point Pg and Pg. to $X$ axis and $Y$ axis, while the angular changing is determined by looking at the changing of $\mathrm{Y}$-axis. The obtained data were analysed with paired $t$ test analysis. The results show that there are significant changes in mandibular position after camouflage orthodontic treatment with fixed appliance of Begg technique $(p<0,05)$. Pg point is shifted towards the posterior and inferior, and $\mathrm{Y}$-axis angle increases. It means that the clockwise rotation has happened.

Maj Ked Gi; Desember 2013; 20(2): 140 - 145.

Keywords: mandibular position, camouflage, class III skeletal, Begg technique

\section{PENDAHULUAN}

Motivasi pasien dalam menjalani perawatan ortodontik pada umumnya adalah karena ingin memperbaiki keserasian dentofasial, yaitu keserasian antara gigi dengan wajah. ${ }^{1}$ Keharmonisan wajah dikaitkan dengan hubungan morfologi dan proporsi hidung, bibir dan dagu. $^{2}$ Keseimbangan antara struktur hidung, bibir dan dagu dipengaruhi oleh pertumbuhan dan perawatan ortodontik. Keseimbangan dan keserasian profil muka dalam diagnosa ortodontik, selain memperhitungkan kedudukan anteroposterior juga melihat kedudukan dagu terhadap kepala. ${ }^{3}$ 
Analisis perubahan posisi mandibula terhadap profil jaringan keras wajah diukur berdasarkan hubungan maksilo-mandibular dan kedudukan dagu terhadap basis cranium. ${ }^{4}$ Downs sit Kusnoto, ${ }^{5}$ menyatakan bahwa posisi mandibula sangat berperan dalam menentukan profil "ideal" wajah seseorang. Bentuk wajah yang dikatakan ideal oleh kebanyakan orang adalah posisi mandibula ortognatik, bukan posisi retrusi atau protusi.

Metode pengukuran sefalometri harus memperhitungkan kedudukan dagu agar dapat mencerminkan gambaran profil jaringan keras yang sebenarnya. ${ }^{6}$ Ramos dan Martenelli, ${ }^{7}$ memperhitungkan kedudukan dagu terhadap kepala, yang dapat digunakan untuk menilai kedudukan mandibula. Phan $\mathrm{dkk}^{8}$ menentukan perubahan posisi mandibula dengan melihat perubahan posisi pogonion (pog). Pengukuran linear horizontal atau sagital pogonion terhadap sumbu vertikal menunjukkan pergerakan mandibula ke muka atau ke belakang. Pengukuran linear vertikal pogonion terhadap sumbu horizontal menunjukkan pergerakan mandibula ke depan atau ke bawah. Perubahan anguler menggunakan sudut $\mathrm{Y}$-axis, menentukan posisi dagu ke bawah, ke depan atau ke depan terhadap wajah atas. Penurunan $\mathrm{Y}$-axis pada sefalogram lateral dapat diinterpretasikan lebih besarnya pola pertumbuhan horizontal daripada pola pertumbuhan vertikal. Peningkatan $Y$-axis menunjukkan pertumbuhan vertikal melebihi pertumbuhan horizontal mandibula. ${ }^{4}$

Maloklusi kelas III merupakan maloklusi yang bersifat progresif pada rahang bawah yang bila tidak dirawat secara intensif dan sedini mungkin, maloklusi akan berkembang terus semakin memburuk dan mengakibatkan cacat muka. ${ }^{9}$ Profil wajah yang cekung sangat mudah diidentifikasi, sehingga pasien dapat mengalami penderitaan psikososial sejak masa anak-anak. Profil wajah pasien dengan deformitas kelas III skeletal selalu menjadi alasan utama yang digunakan untuk mencari perawatan. ${ }^{10}$

Karakteristik kelas III adalah menonjolnya dagu, sejumlah penulis menganggap bahwa prognatisme merupakan ekspresi pertumbuhan yang melewati batas normal, sedangkan penulis lain meyakini bahwa deformitas tersebut menggambarkan perubahan pola pertumbuhan." Pola pertumbuhan mandibula ke bawah dan depan lebih cepat daripada wajah bagian tengah, pertumbuhan mandibula ke arah horisontal lebih dominan dan cenderung memperparah maloklusi kelas III. Pola pertumbuhan tersebut menyebabkan mandibula lebih maju daripada maksila. ${ }^{10}$

Prinsip dasar perawatan maloklusi kelas III adalah memperbaiki relasi skeletal dalam arah anteroposterior. $^{3}$ Perawatan kelas III biasanya meliputi modifikasi pertumbuhan atau menggunakan face mask untuk protraksi maksila, kompensasi dento alveolar atau perawatan kamuflase yang melibatkan pencabutan gigi dan perawatan bedah ortognatik." Perawatan maloklusi kelas III pada pasien dewasa terbatas pada kombinasi perawatan ortodontik dan pembedahan atau perawatan ortodontik kamuflase dengan pencabutan gigi, tergantung keparahan maloklusi. ${ }^{12}$ Perawatan kamuflase non pembedahan pada pasien dewasa dengan maloklusi kelas III memerlukan pencabutan dua gigi premolar mandibula atau empat gigi premolar untuk memberikan ruang retraksi gigi incisivus mandibula. ${ }^{13}$

Salah satu pilihan perawatan ortodontik untuk maloklusi kelas III adalah alat cekat teknik Begg. Prinsip perawatan teknik Begg adalah mekanisme gaya differensial dengan menggunakan gaya yang ringan dan kontinyu. Tahapan dalam perawatan maloklusi kelas III adalah general alignment, koreksi reverse overjet dan overbite. ${ }^{14}$ Overbite normal diperoleh dengan menggunakan elastik intermaksiler kelas III, sedangkan reverse overjet dikoreksi melalui protraksi insisivus atas dan retraksi insisivus bawah. ${ }^{15}$

Penggunaan elastik intermaksiler kelas III menyebabkan rotasi maksila ke depan, ekstrusi gigi molar atas, retrusi gigi insisivus bawah, rotasi mandibula searah jarum jam dan perubahan posisi kondilus. $^{16}$ Perubahan posisi kondilus ditandai dengan pergerakan titik kondilion ke anterior sehingga secara tidak langsung menyebabkan posisi mandibula ke posterior yang akan berpengaruh terhadap posisi dagu. ${ }^{17}$ Posisi dagu tersebut dilihat dari anteroposterior titik pogonion..$^{18}$ Rotasi mandibula searah jarum jam menyebabkan perubahan sudut 
bidang mandibula dan posisi anteroposterior titik pogonion. ${ }^{19}$ Tujuan dari penelitian ini untuk mengetahui perubahan posisi jaringan keras dan jaringan lunak mandibula setelah perawatan kamuflase maloklusi kelas III skeletal dengan alat cekat teknik Begg.

\section{METODE PENELITIAN}

Obyek penelitian adalah sefalogram lateral sebelum dan setelah selesai perawatan ortodontik maloklusi kelas III skeletal dari pasien yang dirawat karyasiswa Program Pendidikan Dokter Gigi Spesialis Program Studi Ortodonsia Fakultas Kedokteran Gigi Universitas Gadjah Mada Yogyakarta 2006-2012, dengan kriteria sebagai berikut: 1) maloklusi Angle kelas III dengan hubungan skeletal kelas III yang dirawat dengan teknik Begg; 2) umur 18-25 tahun; 3) telah selesai perawatan.

Penapakan menggunakan kertas asetat dengan pensil $4 \mathrm{H}$ di atas iluminator. Penapakan sefalogram dilakukan oleh operator yang sama. Bidang dan titik referensi yang digunakan adalah: a) S: Sella; b) N: Nasion; c) Or: Orbital;d) Go: Gonion; e) Pg: Pogonion; f) FHP; g) $\mathrm{Y}$ - axis; h) Garis X: bidang horizontal yang dibentuk 7 derajat ke arah superior dari sella melalui nasion; i) Garis $\mathrm{Y}$ : bidang vertikal yang dibentuk tegak lurus dengan sumbu $X$ melalui nasion. (gambar 1)

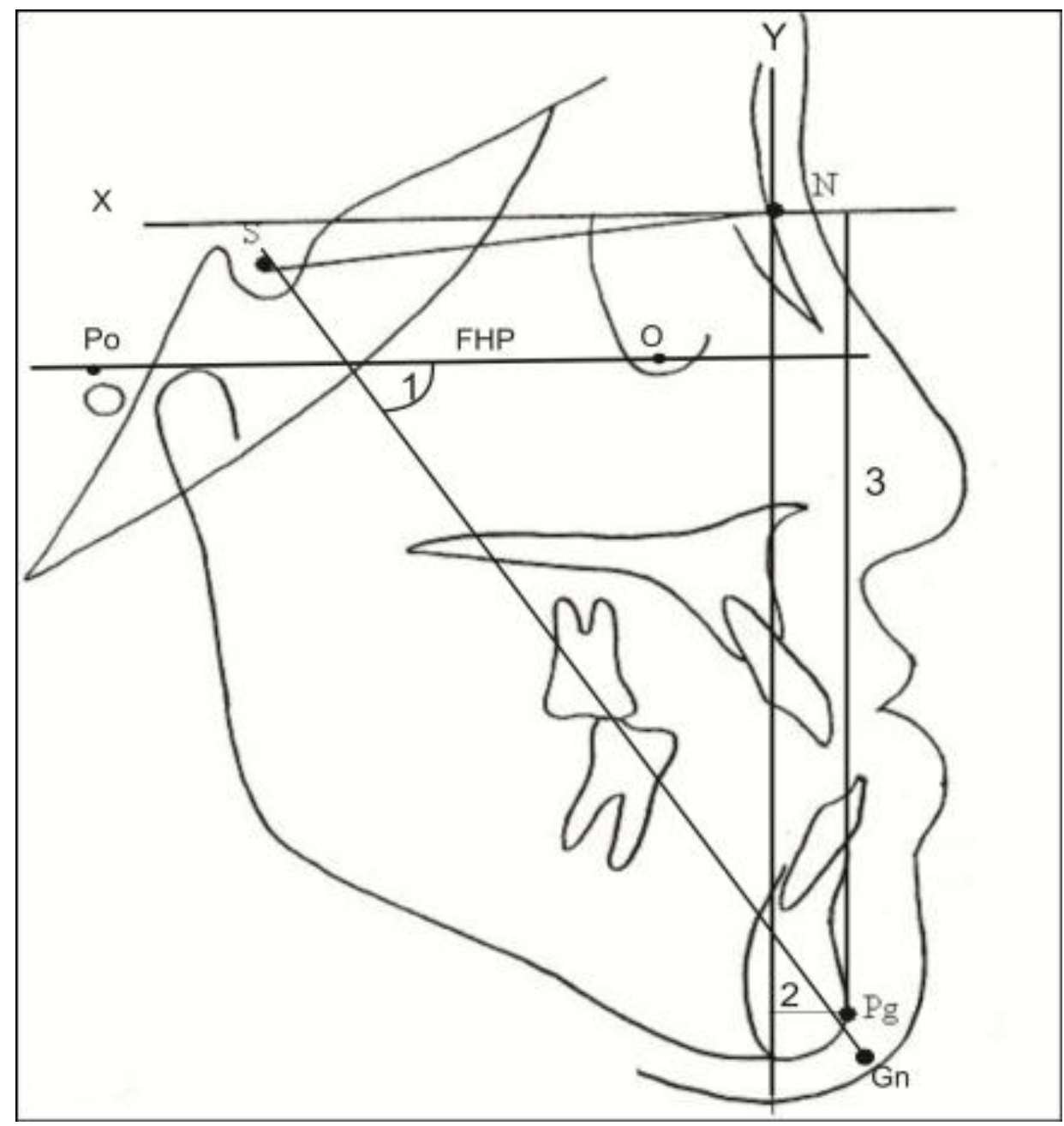

Gambar 1. Pengukuran linier dan anguler posisi mandibula. 1) Sudut Y-axis; 2) Jarak titik Pg terhadap sumbu Y; 3) Jarak titik Pg terhadap sumbu X(modifikasi dari Chew,2005) 


\section{HASIL PENELITIAN}

Penelitian mengenai perubahan linier dan anguler posisi dagu pada perawatan kamuflase maloklusi kelas III skeletal dengan teknik Begg telah dilakukan di Laboratorium Ortodonsia Fakultas Kedokteran Gigi Universitas Gadjah Mada Yogyakarta. Penelitian dilakukan pada 20 sampel yang memenuhi kriteria penelitian (5 laki-laki dan 15 perempuan) sebelum dan sesudah perawatan aktif dari tahun 2006 sampai tahun 2012 (tabel 1).

\section{PEMBAHASAN}

Perubahan posisi titik $\mathrm{Pg}$ terhadap sumbu $X$ dan $\mathrm{Y}$, perubahan sudut $\mathrm{Y}$-axis diukur sebelum dan sesudah perawatan ortodontik, dihitung rerata dan simpangan baku masing-masing variabel penelitian. Berdasarkan rerata dan simpangan baku jarak titik Pg-Y, Pg-X, sudut Y-axis dilakukan analisis Paired t-test. Hasil analisis yang didapatkan tercantum pada tabel 1

Perawatan ortodontik dapat mengubah posisi dagu pasien, kombinasi rotasi mandibula dengan pertumbuhan dan pergerakan kondilus dalam fossa glenoidea yang berperan dalam terjadinya variasi posisi anteroposterior pogonion. Rotasi berkaitan dengan pergerakan pogonion, memprediksikan adanya pergerakan pogonion sejauh 0,649 mm untuk setiap $1^{\circ}$ rotasi. ${ }^{17}$ Perawatan maloklusi kelas III skeletal dengan perawatan kamuflase umumnya memerlukan pencabutan gigi premolar satu bawah untuk mengkoreksi cross bite dengan menggunakan elastik intermaksiler kelas $111 .{ }^{12}$

Sudut Y-axis menunjukkan perubahan yang bermakna $(p<0,05)$, sudut $Y$-axis mengalami peningkatan, berarti terjadi rotasi searah jarum jam. Elastik intermaksiler kelas III dengan anchorage bend dapat menghasilkan intrusi gigi anterior bawah, ekstrusi gigi molar rahang atas dan rotasi mandibula ke belakang. ${ }^{14}$ Sesuai dengan pendapat Nanda, ekstrusi gigi posterior dapat mengakibatkan perubahan skeletal yang ditandai dengan rotasi mandibila searah jarum jam dan peningkatan tinggi muka anterior bawah. ${ }^{20}$

Perubahan linier jaringan keras dagu (jarak Pg-Y) sebelum dan sesudah perawatan menunjukkan perubahan yang bermakna $(p<0,05)$. Titik Pg mengalami penurunan jarak terhadap sumbu $\mathrm{Y}$, berarti titik $\mathrm{Pg}$ berubah ke arah posterior sesudah perawatan sehingga profil lebih lurus, Perubahan titik Pg-X menunjukkan perubahan yang bermakna $(p<0,05)$. Titik Pg mengalami penambahan jarak terhadap sumbu $X$ berarti titik $\mathrm{Pg}$ berubah lebih ke inferior

Tabel 1. Perubahan linier dan anguler posisi dagu

\begin{tabular}{llllll}
\hline Variabel & & Rerata & Simpangan baku & t & P \\
\hline Pg $-\mathrm{Y}$ & Sebelum perawatan & $3,2350 \mathrm{~mm}$ & 5,35725 & 4,422 & $0,000 *$ \\
& Sesudah perawatan & $1,1500 \mathrm{~mm}$ & 4,79707 & & \\
Pg- X & Sebelum perawatan & $117,2827 \mathrm{~mm}$ & 7,53942 & $-6,438$ & $0,000 *$ \\
& Sesudah perawatan & $119,9968 \mathrm{~mm}$ & 7,40485 & & \\
Y-Axis & Sebelum perawatan & $64,5568^{\circ}$ & 4,51580 & \multirow{2}{*}{$-4,953$} & $0,000 *$ \\
& Sesudah perawatan & $66,3520^{\circ}$ & 4,58170 & & \\
\hline
\end{tabular}

\section{Keterangan :}

* $\quad$ : bermakna $(p<0,05)$

$\mathrm{N} \quad$ : jumlah sampel

Pg-Y : jarak Pogonion jaringan keras terhadap sumbu $Y$

$\mathrm{Pg}-\mathrm{X}$ : jarak Pogonion jaringan keras terhadap sumbu $X$

$\mathrm{Y}$ - axis : sudut yang dibentuk oleh garis yang menghubungkan sela tursika dan gnathion dengan FHP 
sesudah perawatan sehingga tinggi muka vertikal muka bagian bawah semakin panjang. Titik Pg mengalami perubahan ke posterior dan inferior karena pada perawatan ortodontik dengan teknik Begg menggunakan elastik intermaksilaris kelas III dan anchorage bend yang menyebabkan terjadinya ekstrusi molar atas dan intrusi gigi-gigi anterior bawah. Sesuai dengan pendapat Caputo dkk, bahwa penggunaan elastik intermaksiler kelas III bersamaan dengan anchorage bend menghasilkan intrusi gigi anterior bawah, ekstrusi gigi molar rahang atas, rotasi mandibula ke belakang dan perubahan posisi kondilus Ekstrusi molar atas yang terjadi karena gaya vertikal elastik kelas III dan anchorage bend menyebabkan terjadinya bite opening. ${ }^{15}$ Rotasi mandibula searah jarum jam menyebabkan perubahan sudut bidang mandibula dan posisi titik pogonion bergerak ke posterior ${ }^{20}$. Hasil penelitian ini sesuai dengan pendapat Wick Alexander, yang menyatakan bahwa elastik kelas III dapat dipakai untuk mengoreksi pola skeletal kelas III dengan cara bite opening dan rotasi mandibula searah jarum jam karena elastik kelas III akan meletakkan kondilus dalam posisi yang lebih ke distal dalam fossanya untuk mengatasi cross bite. ${ }^{21}$

\section{KESIMPULAN}

Kesimpulkan penelitian ini adalah terdapat perubahan linear posisi mandibula menjadi lebih ke belakang dan ke bawah dan perubahan anguler posisi mandibula sudut Y-axis menjadi lebih besar berarti terjadi rotasi searah jarum jam. perubahan posisi mandibula pada perawatan ortodontik kelas III skeletal dan pseudo kelas III masih perlu penelitian lebih lanjut untuk mengkonfirmasi dugaan adanya perubahan pada posisi kondilus.

\section{DAFTAR PUSTAKA}

1. Waldman $\mathrm{BH}$. Lip countour with maxillaly incisors retraction. Angle Orthod. 1982; 52: 129-134.

2. Moseling KP, Woods MG. Lip curve change in females with premolar extraction or nonextraction treatment. Angle Orthod. 2004; 74: 51-62.
3. Bibby RE. A Cephalometri study of sexual dimorphism. Am. J. Orthod. 1979; 5(6): 256-59.

4. Jacobson A. Radiographic cephalometry: from basics to video imaging. Chicago : Quintessence Publishing Co; 1995. H. 224, 241-2, 249.

5. Kusnoto $\mathrm{H}$. Penggunaan cephalometric radiografi dalam bidang orthodonti. Jakarta: Bagian Orthodonti FKG Universitas Trisakti; 1977. H. 3-15

6. Linquist JT. The lower incisor influence of treatment and estetica. Am. J. Orthod. 1978; 444:112-140.

7. Ramos DSP, Martenelli E. Longitudinal evaluation of the skeletal profil of treated and untreated skeletal class II individual. Angle Orthod. 2004; 75(1): 47-63.

8. Jacobson Evan WG, Preston, CB, Swadowsky PL. Mandibular prognatism. Am. J. Orthod. 1974; 66 (2): 140-171.

9. Lin J, Gu Y. Preliminary investigation of nonsurgical treatment of severe skeletal class III malocclusion in the permanen dentition. Angle Orthod. 2003; 73: 401-410.

10. Graber, Swain BF. Orthodontics current principles and techniques. St. Louis: The C.V. Mosby Company. 1985: 381-390.

11. Proffit, Fields HW. Contemporary orthodontic. Ed 3. St Louis: Mosby; 2000. H. 276-81.

12. Daher W, Caron J, Wechler MH. Non surgical treatment of an adult with a class iii malocclusion. Am J Orthod Dentofac Orthop. 2007; 132: 243-51.

13. Fletcher GGT. The Begg appliance and technique. Briston London: John Wright \& Sons Ltd;1981. H. 34-48.

14. Rosedano A. Incisor movement in class III malocclusion treated with the begg light wire technique. Am. J. Orthod. 1971; 60(4): 355-67

15. Caputo AA, Levy JAA, Chaconas SJ. Effecs of orthodontic intermaxillary class III mechanics on craniofacial struktures part II-computerized cephalometrics. Angle Orthod. 1979; 49(1): 29-36

16. Vardimon AD, Graber TM, Stutzman J, Voss L, Petrovic AG. Reaction of pterygomaxillary fissure and the condylar cartilago to intermaxillary class III mechanics. Am J Orthod Dentofac Orthop. 1994; 105: 401-13. 
Sri Hartati., dkk.: Perubahan Posisi Mandibula ...

17. Lahaye MB, Buschang $\mathrm{PH}$, Alexander, Boley JC. Orthodontic treatment change of position in class II division 1 patiens. Am J Orthod Dentofac Orthop. 2006; 130: 732-40.

18. Gianelly, Goldman HM. Biologic basic of orthodontics. Philadelphia: Lean\& Febiger. 1971. H. $116-38$
19. Nanda R. Correction of deep overbite in adults. Dental Clinic of North America, 1997; 41(1): 67-87.

20. Lulla P, Gianelly AA. The Mandibular plane and mandibular rotation. Am J Orthod Dentofac Orthop. 1976; 70(5): 567-71.

21. Wick Alexander RG. Teknik Alexander Konsep dan Filosof Kontemporer. Penerjemah B Susetyo. Editor L Yuwono. Jakarta: EGC; 1996 H.138-40. 